\title{
NORMAL DIAMETER OF THE HEART IN RADIOGRAPHS OF PRE-SCHOOL CHILDREN
}

\author{
BY \\ DAVID HEWITT \\ From the Department of Social Medicine, Oxford University
}

(RECEIVED FOR PUBLICATION SEPTEMBER 20, 1957)

Over a period of several years children in the Oxford Child Health Survey had a chest radiograph taken at six-monthly intervals. As part of a genetic study measurements of the breadth of the heart shadow have been made on all those children who had brothers or sisters in the Survey. The chest radiograph was dropped from the routine examination some years before the end of the Survey but sufficient measurements have been taken to provide reasonable estimates of the average heart diameter of healthy children up to the age of 5 years. A summary of these measurements is presented here in the hope that it may provide a useful standard of comparison for children in whom enlargement of the heart is suspected.

Possibly the most usual radiographic criterion of normal heart size is the cardiothoracic index (total transverse heart diameter divided by internal diameter of the thorax), a value in excess of 0.50 being taken as prima facie evidence of enlargement.

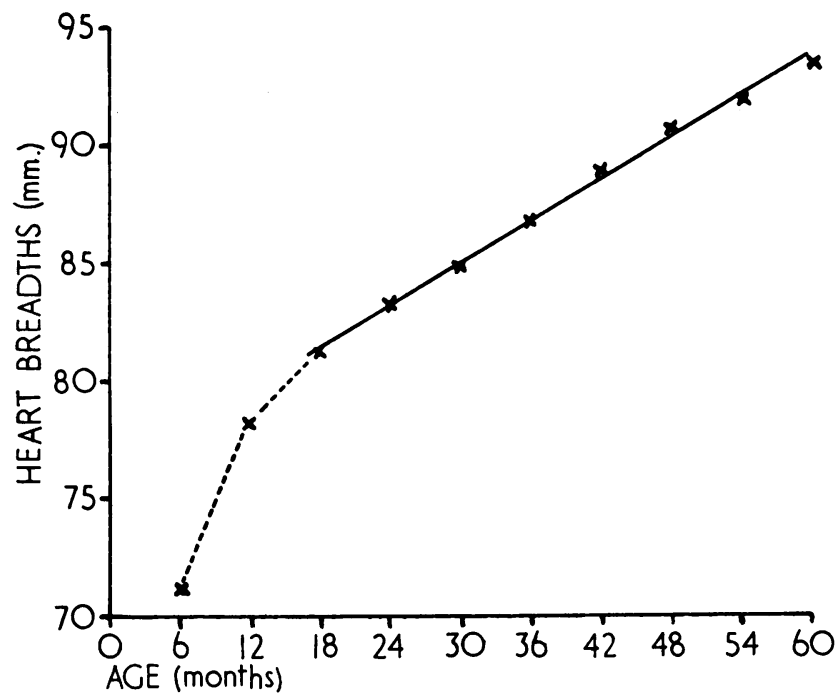

Fig. 1.-Mean radiographic heart diameter of Oxford children aged 6 months to 5 years: mixed series of boys and girls.
However, this ratio has certain disadvantages in early childhood when it is difficult to control the phase of respiration during exposure. In young children also the long axis of the heart is inclined at a much more shallow angle to the transverse axis of the thorax than in later life, so that healthy infants may exhibit a cardiothoracic index well in excess of 0.50. Bakwin and Bakwin (1935) concluded that age-standards for total transverse diameter provide as good a guide to normal heart size as the cardiothoracic index. This index has therefore not been calculated for the Oxford children and the present report is concerned only with absolute measurements.

All films were taken in the anterior posterior direction using a focal-film distance of $4 \frac{1}{2}$ feet (1.37 metres). The child was posed sitting in an erect position and an attempt was made to take the picture at full inspiration, although this was not always possible, especially with the younger children. Following Caffey (1945) heart diameter was taken as, "the sum of the greatest perpendicular distance from the midline of the thorax to the right cardiac margin and the greatest distance from the midline to the left cardiac border'. Measurements were read directly from the film with a transparent rule marked in half-centimetre units.

The apparent diameter on any individual film will, of course, depend to a considerable extent on the phase of the heart-beat at the moment of exposure. In view of the number of children measured at each age this source of variation has probably had a negligible effect on the averages, but, together with other errors, will certainly have inflated the estimated standard deviations and thus broadened the range of 'normal' diameter. This point is discussed below in connexion with Fig. 2.

Mean heart diameters at ten ages are shown in Fig. 1 for all children measured, without distinction of sex. It will be seen 
that the increase in heart diameter between the ages of 6 and 12 months is about $7 \mathrm{~mm}$. and in the following six months about $3 \mathrm{~mm}$. Thereafter the mean diameter increases very regularly at a rate of between 3 and $4 \mathrm{~mm}$. per year. The linear correlation coefficient between age and mean heart diameter over the range 18 months to 5 years is +0.9986 , a degree of correlation which justifies the use of a fitted regression line for estimating normal diameters in this age range. Such a line is also shown in Fig. 1.

The means and standard deviations at each age for boys and girls separately are shown in Table 1. Throughout the first five years of life the mean breadth is greater for boys than for girls by an amount which ranges from $2 \frac{1}{2}$ to $4 \frac{1}{2} \mathrm{~mm}$. but which may reasonably be regarded, after allowance for sampling fluctuations, as a fairly constant $3 \frac{1}{2} \mathrm{~mm}$. The standard deviation also tends to be greater for boys than for girls by an amount which, on average, is slightly more than proportional to the difference in means. However, for practical purposes, the coefficient of variation

$$
\left(\frac{\text { standard deviation }}{\text { mean }} \times 100\right)
$$

may be regarded as the same for each sex and, over the ranges 18 months to 5 years it may also be regarded as constant from age to age at about $6.2 \%$.

These regularities in the data make it possible to draw a simple channel for the normal heart diameter of healthy young children, and this has been done in Fig. 2. The boundaries of this channel have been drawn at distances of two standard deviations above and below the mean, that is, they should include rather more than $95 \%$ of measurements

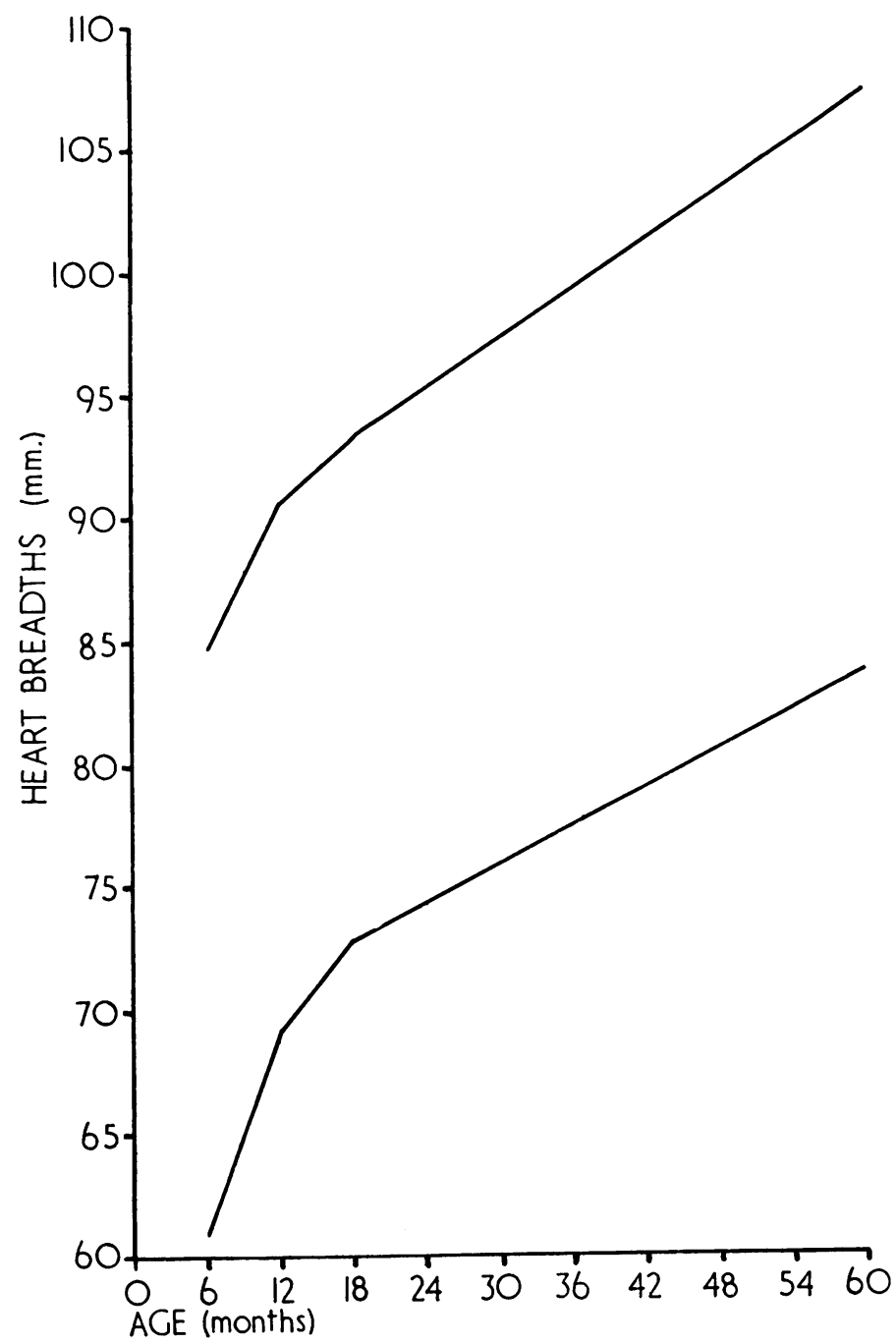

FIG. 2.- Normal channel of heart growth in young children. Approximately $95 \%$ of films of boys taken under the stated conditions should yield measurements between these limits. To compare a girl's heart diameter with these standards first add $3 \frac{1}{2} \mathrm{~mm}$.

TABLE 1

MEAN AND STANDARD DEVIATION OF RADIOGRAPHIC HEART DIAMETER OF OXFORD BOYS AND GIRLS AGED 6 MONTHS TO 5 YEARS

\begin{tabular}{|c|c|c|c|c|c|c|c|c|c|c|c|c|c|}
\hline & & & & & & & & Age in & Months & & & & \\
\hline & & & & 6 & 12 & 18 & 24 & 30 & 36 & 42 & 48 & 54 & 60 \\
\hline Boys & $\begin{array}{l}\text { No. measured } \\
\text { Mean (mm.). } \\
\text { Standard deviation }\end{array}$ & $\begin{array}{l}. \\
\therefore \\
\cdots\end{array}$ & $\begin{array}{l}\cdots \\
\cdots \\
\cdots\end{array}$ & $\begin{array}{l}98 \\
73 \cdot 2 \\
6 \cdot 2\end{array}$ & $\begin{array}{r}106 \\
79 \cdot 8 \\
5 \cdot 2\end{array}$ & $\begin{array}{r}101 \\
82 \cdot 7 \\
5 \cdot 2\end{array}$ & $\begin{array}{r}94 \\
84 \cdot 8 \\
5 \cdot 1\end{array}$ & $\begin{array}{r}74 \\
86 \cdot 9 \\
4 \cdot 8\end{array}$ & $\begin{array}{r}73 \\
87 \cdot 9 \\
6 \cdot 1\end{array}$ & $\begin{array}{l}69 \\
91 \cdot 2 \\
5 \cdot 5\end{array}$ & $\begin{array}{r}67 \\
92 \cdot 2 \\
5 \cdot 8\end{array}$ & $\begin{array}{r}56 \\
93 \cdot 8 \\
6 \cdot 4\end{array}$ & $\begin{array}{r}47 \\
96 \cdot 1 \\
6 \cdot 1\end{array}$ \\
\hline Girls & $\begin{array}{l}\text { No. measured } \\
\text { Mean . } \\
\text { Standard deviation }\end{array}$ & $\begin{array}{l}\cdots \\
\cdots \\
\cdots\end{array}$ & $\begin{array}{l}\ldots \\
\cdots\end{array}$ & $\begin{array}{r}104 \\
69 \cdot 4 \\
5 \cdot 4\end{array}$ & $\begin{array}{r}113 \\
76 \cdot 7 \\
5 \cdot 2\end{array}$ & $\begin{array}{r}102 \\
79 \cdot 7 \\
5 \cdot 1\end{array}$ & $\begin{array}{r}97 \\
81 \cdot 6 \\
4 \cdot 9\end{array}$ & $\begin{array}{l}85 \\
83 \cdot 2 \\
5 \cdot 1\end{array}$ & $\begin{array}{r}83 \\
85 \cdot 4 \\
5 \cdot 7\end{array}$ & $\begin{array}{r}74 \\
86 \cdot 8 \\
5 \cdot 4\end{array}$ & $\begin{array}{r}67 \\
88 \cdot 8 \\
5 \cdot 4\end{array}$ & $\begin{array}{l}60 \\
90 \cdot 3 \\
5 \cdot 0\end{array}$ & $\begin{array}{l}60 \\
91 \cdot 4 \\
5 \cdot 3\end{array}$ \\
\hline
\end{tabular}


healthy children taken under the stated conditions should show a heart diameter greater than that indicated by the upper line. The figure has been drawn for use as a standard for boys, but it may also be used to assess girls' measurements if these are first increased by $3 \frac{1}{2} \mathrm{~mm}$. The channel is strikingly wide: a heart diameter of $84 \mathrm{~mm}$. could be regarded as just within normal limits both at 6 months and at 5 years. However, as stated above, the true range of variability will have been somewhat exaggerated as a result of certain errors inherent in the measurements. From calculations based on successive measurements of the same children it can be inferred that the channel might have been narrower by about one-fifth if the measurements from which it is derived has been free from error. If several films of the same child exhibit heart diameters outside the limits of Fig. 2, or with an average outside them, there is, of course, a much stronger presumption of abnormality than when an isolated film falls outside these $95 \%$ limits.

No attempt has been made here to incorporate an allowance for general body size, but it must be borne in mind that children who are markedly large or small for their age must be expected to have rather larger or smaller hearts. In the present study it has been found (on the basis of assessments combining successive measurements of the same children) that heart diameter at a given age is correlated with body weight to the extent of +0.437 . There is also a normal tendency for large or small hearts to run in a family, the sib-sib correlation of heart diameter in the Oxford data (again based on a combination of successive measurements) being $+0 \cdot 367$.

Bakwin and Bakwin (1935) have published radiographic measurements of the heart diameters of a group of New York children taken at monthly intervals during the first year of life. Their figures emphasize the relatively rapid growth of the heart during the earliest months of life: the average gain in the first six months was $19 \mathrm{~mm}$. (from 49 to $68 \mathrm{~mm}$.) compared with only $7 \mathrm{~mm}$. (from 68 to $75 \mathrm{~mm}$.) in the remainder of the first year. Thus, the gain between the ages of 6 months and 1 year was the same as found in the present study, although the New York children (who were described as coming from 'very poor homes') had slightly narrower hearts on average than post-war Oxford children of corresponding age. (After allowing for a slight difference in magnification the margin is about $2 \mathrm{~mm}$.) The heart measurements of Denver children given by Maresh (1948) for children from the age of 4 years onwards are based on posterior anterior exposures and therefore cannot easily be compared with the present series. However, they agree with the Oxford measurements in showing a greater average heart diameter for boys than girls at the ages of 4 and 5 years, and also a similar degree of correlation with height and with weight.

\section{Summary}

Measurements of chest films taken in the course of the Oxford Child Health Survey have been used to set up approximate standards of normal heart diameter for children aged 6 months to 5 years.

All the films used in this study were taken by Miss Eleanor Roberts and Miss Margaret Barnes. I am indebted to Dr. W. Pennybacker for advice on the measuring technique. The Oxford Child Health Survey is supported by a grant from the Medical Research Council.

\section{REFERENCES}

Bakwin, H. and Bakwin, R. M. (1935). Amer.J. Dis. Child., 49, 861. Caffey, J. (1945). Pediatric X-Ray Diagnosis. Chicago.

Maresh, M. M. (1948). Pediatrics, 2, 382. 